The Economic Journal, ro6 (March), 387-400. (c) Royal Economic Society 1996. Published by Blackwell Publishers, 108 Cowley Road, Oxford OX 4 IJF, UK and 238 Main Street, Cambridge, MA 02142 , USA.

\title{
UNEMPLOYMENT DURATION AND THE RESTART EFFECT: SOME EXPERIMENTAL EVIDENCE*
}

\author{
Peter Dolton and Donal O'Neill
}

\begin{abstract}
In this paper we analyse the effect of the Restart programme in the United Kingdom. This programme consists of an interview of the long-term unemployed to counsel them on effective job search. Failure to attend the interview carries the threat of the cessation of unemployment benefits. The results, using experimental data, indicate that the programme has a significant effect of reducing unemployment duration. Estimation of an independent competing risks model distinguishing between exits from unemployment to: a job, a training placement or to signing-off unemployment benefit shows that the channels through which Restart works differs according to exit type.
\end{abstract}

The recent growth in the number of long-term unemployed, is viewed as one of the most important problems facing the UK economy. ${ }^{1}$ Various interventionist government policies have been suggested to help unemployed workers maintain a better link with the labour market. Some of the most recent policies, including suggestions for a 'Jobseeker's Allowance' (HMSO, I994), focus on providing an additional incentive to the unemployed to seek work and no longer claim unemployment benefit (UB). In this study we estimate the extent to which one such scheme, the Restart programme, has succeeded in helping the long-term unemployed return to the labour market.

Recent studies which attempt to evaluate the potential of government schemes to reduce unemployment and to provide workers with the necessary skills needed to maintain a strong link with the labour market, have highlighted the problems posed by non-random selection into such programmes. The resulting sample selection bias can severely contaminate estimates of the programme's effectiveness. The use of controlled experiments has been advocated as a means of overcoming this problem. ${ }^{2}$ Our study allows such an evaluation of the Restart effect since the analysis is based on a controlled experiment, in which a purely random subset of the sample was excluded from the scheme. ${ }^{3}$ The presence of such a control group allows us to obtain unbiased estimates of the 'treatment effect' of the Restart programme in altering the unemployment patterns of participants.

* We are grateful to Michael White, Jon Hales, the PSI and the SCPR for help in accessing the data and to Tony Atkinson, Audra Bowlus, Ken Burdett, Guido Imbens, Tony Lancaster, Gerard Van den Berg, Wilbert Van der Klaauw as well as two anonymous referees and seminar participants at Newcastle University, Dublin Economics Workshop and the EMRU Labour workshop for comments and suggestions. Peter Dolton would like to thank the ESRC for funding towards this research from research grant numbers Rooo2339o9 and $\mathrm{H}_{5} 19255006$. This paper was written whilst O'Neill was at the University of Newcastleupon-Tyne. We alone are responsible for any errors.

${ }^{1}$ Between 1979 and 1986 the proportion of unemployed who had been out of work for over a year rose from $20 \%$ to around $40 \%$ in Britain.

2 See LaLonde (1985).

${ }^{3}$ To our knowledge the data set used in this study is one of the first modern attempts to collect experimental data in labour market policy evaluation in the United Kingdom. We are aware only of the work of Royston (1983) and (1984) using a DHSS sample and the work of White and Lakey (1992) which uses the same data as the present study. 
The Restart programme consists of a compulsory interview for each unemployed person in the United Kingdom after they have been registered as unemployed for 6 months. The interview with an official of the Employment Office is designed to help unemployed people find a job and reduce their dependency on unemployment benefits. In part it achieves this by placing workers in contact with employers or training agencies. Hence, an important part of the Restart process is the positive help and encouragement given to unemployed job seekers by the way of advice, counselling and direct contact with employers. Such positive intervention is commonplace in other OECD countries. However, a crucial feature of Restart is that it also has a negative threat component, in that the UB claimant is faced with the possibility of having their benefits reduced or suspended if they do not attend the Restart interview or are not deemed to be making genuine attempts to find a job. While previous studies have looked at the effect of a change in the arrival rate of wage offers, there have been (to our knowledge) few attempts to assess the effect of a threat of unemployment benefits reduction on unemployment duration. Several papers have modelled the effect of unemployment benefit regime changes after a specified number of months, e.g. Meyer (1990), Katz and Meyer (1990) or calculated the elasticity of reservation wages with respect to benefits. ${ }^{4}$ However, unlike the present study, none were in a position to assess the effect of a threat to suspend unemployment benefits.

In this paper we examine the channels through which Restart works by distinguishing between the different possible routes out of unemployment and examining the extent to which the Restart programme has a different impact on distinct exit types. This is modelled as a competing risks exit process from unemployment into: a job, a training placement or signing-off unemployment benefits. Our findings show that the impact of Restart differs according to the exit type. In particular, the results indicate that the receipt of a Restart interview greatly increases the hazard to signing off, irrespective of when the interview takes place, however, being in the control group (i.e. receiving the interview 6 months later) may have a lasting negative effect on job prospects.

\section{THE RESTART PROGRAMME IN I 989}

The Restart programme was introduced by the government in April 1987 to review the position of people experiencing long-term unemployment. ${ }^{5}$ In this section we describe how the system worked at the time our data were collected. The programme consisted of a set of six-monthly meetings between the unemployed individual and a counsellor. During this interview the counsellor assessed the claimant's recent unemployment history and offered advice on benefits, search behaviour, training courses and in some instances initiated direct contact with employers. The main aim of the Restart process was to

4 See Lancaster and Chesher (1983).

${ }^{5}$ While the goals of the Restart programme in operation today are the same as those in 1987, the programme has developed substantially since its introduction. In particular, today's system is a 'seamless' process of continued appraisal of the unemployed person's job search, suitability for training and eligibility for welfare. Further details are available in a Supplementary Appendix available from the authors upon request. 
reduce the amount of time people spend unemployed and reduce claims of unemployment benefit by those who were essentially not available for work or who were not making the appropriate effort to find employment.

While the Restart process may have affected unemployed claimants in several ways, a direct consequence of the process was the threat to reduce or suspend a claimant's welfare receipts. The Child Poverty Handbook (I993) describes the process thus:

'If you decline all offers of assistance, your case will be referred to an adjudication officer who may decide either that you are not really available for work or, if you have refused an offer of employment or training, that you should be disqualified from benefit for a specific period.' (page I 7).

it goes on to suggest that:

'Looking for a job can be difficult, depressing and frustrating experience and many claimants find Restart interviews - and in particular having to justify their attempts to find work to a person in authority under the threat that their benefits may be stopped - very intimidating.' (page 17).

The process started with the Restart office sending a letter to each individual approaching an unbroken period of six months claiming unemployment benefit. This letter requested that the individual attend an interview at a stated date and time. Interviews took place in Employment Service Job Centres and lasted approximately $15^{-25}$ minutes. In some instances individuals were excused attendance at the Restart interview mainly because they had already obtained a job or a place on a training programme or had withdrawn their benefit claim. On completing the interview the Restart counsellors then recommended a course of action for that individual designed to help them in their job search.

Attendance at the Restart interview was mandatory, in that it is a condition of receiving benefits that claimants attend an employment interview when asked to do so. Those who failed to attend the initial appointment were sent two more letters requesting them to do so. If they still had not attended an interview by the time of the third letter their names were flagged at the Unemployment Benefit Office and they were then required to attend a Restart interview and to return with evidence of having done so, before they are allowed to sign on to receive unemployment benefits.

\section{D A T A}

In 1989 the Policy Studies Institute was commissioned by the Employment Service to evaluate the impact of Restart. This study identified a sample of individuals approaching their 6th month of unemployment in the period March-July 1989 who were eligible for a Restart interview. A random sample of 8,925 of these individuals was chosen to take part in the study. Individuals were retained in the sample even if they subsequently did not attend a scheduled interview, as such the sample is one of the inflow to Restart and not the outflow from it. Every Employment Service office throughout Britain was 
contacted while constructing the sample in order to eliminate regional biases. Individuals were selected for the sample from the inflow lists on the basis of their National Insurance (NI) numbers. The NI digit sequence used correspond to those used by the JUVOS Cohort data base and is known to result in a random $5 \%$ sample. Of this set a control group of 582 people was randomly chosen, again by means of previously specified NI digit sequences. Members of the control group, although eligible for an interview, were not asked to attend the initial Restart interview. For each individual in the sample, data were collected on personal characteristics such as sex, age as well as information on the Restart interview and outcome. About 6 months after the Restart Interview, the survey organisation, Social and Community Planning Research conducted a survey of these individuals in which detailed information was obtained on subsequent work history, personal characteristics, the Restart interview, previous employment history, job search behaviour and benefit income. Of the original sample, 5,200 individuals completed this survey, which was conducted between September and October 1989. Approximately half of the non-responses resulted from an inability to contact the individual due to invalid address records or death, whereas the other half refused to take part in the survey. ${ }^{6}$ Of the 5,200 respondents, 4,565 satisfied the sampling criterion (i.e. an ongoing spell of unemployment of approximately 6 months), of which 323 were members of the control group. It is this sample which we use in this paper.

The structure of the sample was such that it could be linked to administrative JUVOS data collected by the Employment Service, which provides accurate records on the claimant's unemployment history dating back to January I 982 which can be used to analyse the impact of Restart on movements out of unemployment. ${ }^{7}$ The survey also contained information on an individual's travel to work area which was linked to the National Online Manpower Information System (NOMIS) to obtain monthly data on local labour market conditions dating back to August 1985. A description of the variables used in this study, along with summary statistics are presented in the Data Appendix.

\section{THE IMPACT OF RESTART ON THE DURATION OF UNEMPLOYMENT}

One method of assessing the effect of Restart is to look at the median time in unemployment of the control and treatment groups, which are I3 and 12 months respectively. ${ }^{8}$ Hence, we find that members of the treatment group have unemployment spells which are on average one month shorter than those of individuals in the control group. This estimate of the impact of Restart compares favourably with results of experiments carried out in the United States which estimated reductions in unemployment duration ranging from I to 3 weeks. Woodbury and Spiegelman (1987) assess the impact of a programme which involves paying a benefit bonus to unemployed people who

${ }^{6}$ While attrition from the original sample can potentially lead to bias, estimates of a probit equation determining survey participation show that the decision to participate was independent of control group status. As a result our estimates of the Restart effect are likely to be unaffected by the attrition.

7 We have also carried out the analysis using self-reported data and obtained very similar results.

8 Using the median duration helps limit the impact of censoring on the results.

(C) Royal Economic Society 1996 
obtain employment within II weeks. They find that the scheme reduces average unemployment duration by one week. Johnson and Klepinger (1994) performed an econometric evaluation of a scheme in which receipt of benefits was tied to various work search requirements. They found shorter unemployment durations when such a regime was enforced.

An alternative way of analysing the impact of Restart is to examine the empirical hazard functions by control group status. The results shown in Fig. I

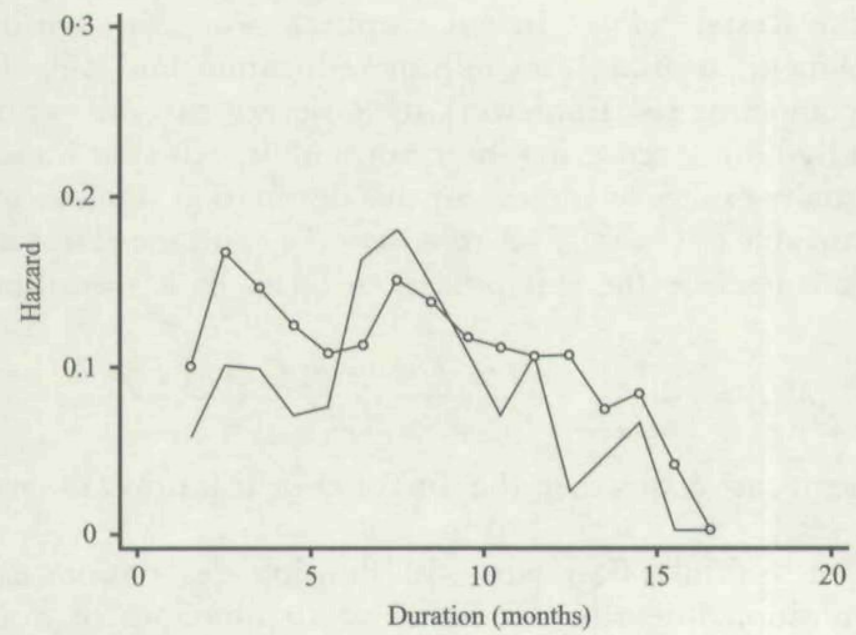

Fig. 1. Kaplan-Meier estimates of the hazard function for both control and treatment group (o).

provides further evidence supporting a role for Restart in reducing unemployment duration. ${ }^{9}$ First, we note the striking difference in the hazard functions for the control and treatment groups in the $5^{-6}$ months following the initial Restart Interview. In particular, we see that over the period in which the control group was excluded from the process, members of this group were only about $70-80 \%$ as likely to exit unemployment as members of the treatment group. ${ }^{10}$ Secondly, we notice a significant spike in the hazard function approximately six months after the initial interview, which is consistent with attendance at the Restart interview after a year's unemployment. At first sight it may seem surprising that the spike is more pronounced for control group members. However, we should remember that control group members were only excluded from the first Restart. They did attend a Restart Interview after a year's unemployment and to the extent that we believe the first meeting with the Restart Counsellor to be the most effective, then the pattern in Fig. I is what one would expect. ${ }^{11}$

9 In what follows we use the zero (reference) duration point as the 6 th month of unemployment, since all our sample have been unemployed for at least six months.

${ }^{10}$ We have estimated confidence intervals for these hazard functions which support the differences discussed in the text. However, in order to keep from cluttering the figure we have not included them in Fig. I.

i1 We have also estimated the effects of Restart by specifying a proportional hazards model with a flexible baseline hazard, allowing for the possibility of unobserved heterogeneity. Again the results showed that Restart significantly reduced unemployment duration (Dolton and O'Neill, 1995).

(C) Royal Economic Society 1996 
IV. THE MULTIPLE EXIT FRAMEWORK OF THE RESTART PROCESS

While these results suggest a role for Restart in reducing the duration of unemployment they provide no evidence on the channels through which the programme works. To do this we distinguish between movements off the register into employment and movements into non-participation. The first may be associated with the guidance and help received from the Restart counsellors, while the latter may result from failing to meet the benefit eligibility criteria specified at the Restart office. In our empirical work we identify three exit states, employment, training and fulltime education and out of the labour force. ${ }^{12}$ In a competing risk framework the observed exit time or duration $t_{i}$ is characterised by both a censoring indicator and an exit type indicator. In the case of $K$ mutually exclusive and exhaustive destination states or exit types, let the random variable $C, C=\mathrm{I}, \ldots, K$ represent the exit type. Then at each point in time we can describe the exit process in terms of $K$ transition intensities defined as

$$
h^{k}(t)=\lim _{d t \rightarrow 0} \frac{\operatorname{Prob}(t \leqslant T<t+d t, C=k \mid T \geqslant t)}{d t} .
$$

The total hazard rate $h(t)$ is then the sum of all $K$ transition intensities at time $t: h(t)=\sum_{k=1}^{K} h^{k}(t)$.

It is common to think of a model with multiple destinations as a model in which the transition intensities are the hazard functions of $K$ independent destination-specific latent duration or survival times. The actual exit time and exit type can then be interpreted as realisations of random variables $T$ and $C$ defined as

$$
\begin{gathered}
T=\min \left(T^{k} ; k=\mathrm{I}, \ldots, K\right), \\
C=\operatorname{argmin}_{k}\left(T^{k} ; k=\mathrm{I}, \ldots, K\right),
\end{gathered}
$$

where the independent random variables $T^{1}, T^{2}, \ldots, T^{K}$ are the latent durations, representing the length of stay before an exit of type $k$ occurs in the absence of all other types of exit risks. With only $C$ and $T$ being observed, this model is often referred to as an independent competing risks model. We will assume that each of the transition intensities are of the proportional hazard type with

$$
h_{i}^{k}(t)=\underline{h}^{k}(t) \exp \left[X_{i}(t)^{\prime} \beta_{k}\right], \quad k=\mathrm{I}, \ldots, K .
$$

Consider the case of 3 exit types $(K=3)$ and the grouped interval data analysed here. Then under the assumption that the durations $T^{1}, T^{2}$ and $T^{3}$ are independent (conditional on $X$ ), it is possible by applying monotonic transformations of the variables to show that for censored observations

$$
\operatorname{Prob}\left(\mathrm{T}^{1}>t_{i}, T^{2}>t_{i}, T^{3}>t_{i}\right)=\operatorname{Prob}\left(\epsilon_{1 i}>J_{1}, \epsilon_{2 i}>J_{2}, \epsilon_{3 i}>J_{3}\right),
$$

where

$$
J_{j}=-\log \int_{0}^{t_{i}} e^{X_{i}(u)^{\prime} \beta_{j}} \underline{h}^{j}(u) d u, \text { for } j=\mathrm{I}, 2,3 .
$$

\footnotetext{
12 It is relatively straightforward to adopt the three state model of Burdett et al. (1984) in order to capture the essence of the Restart process.
} 
and $\epsilon_{1}, \epsilon_{2}$ and $\epsilon_{3}$ are independently distributed extreme value errors (see Han and Hausman (1990)). Similarly, the probability of observing a complete duration $t_{i}$ with exit type $c$ for individual $i$ is

$$
\begin{aligned}
& \operatorname{Prob}\left(t_{i} \leqslant T<t_{i}+\mathrm{I}, C_{i}=c\right)=\operatorname{Prob}\left(t_{i} \leqslant T^{c}<t_{i}+\mathrm{I}, T^{k}>T^{c}\right) \\
& =\operatorname{Prob}\left[-\log \int_{0}^{t_{i}+1} \underline{h}^{c}(u) e^{X_{i}(u)^{\prime} \beta_{c}} d u \leqslant \epsilon_{c i}<-\log \int_{0}^{t_{i}} \underline{h}^{c}(u) e^{X_{i}(u)^{\prime} \beta_{c}} d u, \epsilon_{k i}>m\left(\epsilon_{c i}\right)\right],
\end{aligned}
$$

for $c, k=1,2,3$ and $c \neq k$, where $m\left(\epsilon_{c i}\right)$ represents the value of $\epsilon_{k i}$ such that duration $T^{k}$ implied by that $\epsilon_{k}$ through $\epsilon_{k}=-\log \int_{0}^{T^{k}} \underline{h}^{k}(u) e^{X_{i}(u)^{\prime} \beta_{k}} d u$ equals the duration $T^{c}$ similarly implied by $\epsilon_{c}$.

Notice that the probability in (6) is bounded between Prob $\left(t_{i} \leqslant T^{c}<t_{i}+\mathrm{I}\right.$, $\left.T^{k}>t_{i}\right)$ and $\operatorname{Prob}\left(t_{i} \leqslant T^{c}<t_{i}+\mathrm{I}, T^{k}>t_{i}+\mathrm{I}\right)$. In the case of continuous duration data (i.e. not grouped by interval), the relevant probability will be $\operatorname{Prob}\left(t_{i} \leqslant T^{c}<t_{i}+\Delta, T^{k}>t_{i}\right)$ which is equal to the product of the probability of an exit of type $c$ in interval $\left(t_{i}, t_{i}+\Delta\right)$ times the probability that the duration $T^{k}$ was censored at time $t_{i}$. Accordingly the likelihood consisting of terms like (5) and (6) can be factored into separate components for each risk where failures of the alternative type are treated as censored observations for exit of other types. This implies that hazard functions $h_{1}(t), h_{2}(t)$ and $h_{3}(t)$ can be estimated in the same way single risk models are estimated, by treating exits of other types as censored observations. A similar procedure is possible using group data, if one assumes a particular form for the hazard function inside each interval.

\section{EMPIRICAL RESULTS FOR THE COMPETING RISKS MODEL}

In modelling the different types of exit out of unemployment in the manner set out in Section IV, we also wish to model explicitly two additional considerations. The first is an attempt to capture the role of the Restart in changing the arrival rates of offers. We allow for this in our estimation by including two separate variables in our estimation, which measure whether the person received either a job offer, or a training offer, directly as a result of the Restart process. ${ }^{13}$

The second additional feature which we will model involves a complication in the experimental design. In deriving the results presented in Section III we treated the people not called for a Restart interview as a conventional 'control' group and those who received the interview as a 'treatment' group. However, there is one crucial respect in which the people in the control group are not like a classical experimental control group. In our experiment the 'control' group are only excluded from the first Restart interview at 6 months of unemployment, but they do receive the subsequent Restart interviews at 12 and 18 months of unemployment, provided they remain unemployed. This

\footnotetext{
${ }^{13}$ It is worth noting that receiving an offer did not necessarily imply that the individual accepted the job or training place.
}

(C) Royal Economic Society 1996 
means that to some extent we should also test whether our 'control' group become like the 'treatment' group after they receive their first Restart interview at 12 months. We can examine this hypothesis by constructing a time-varying variable which takes the value of $I$ only when the person has had their first Restart interview. This means that members of the control group have a value of o for this variable up until month 6 (unemployment duration of 12 months), when they have their first Restart interview - provided they do not get into a job before this time. The treatment group have a value of $\mathrm{I}$ for this variable from date I, i.e. from the date at which they get their first Restart interview at 6 months of unemployment. ${ }^{14}$ This time varying covariate has another useful property, in that its inclusion in the hazard function along with the dummy variable indicating membership of the control group, provides a direct test for the validity of the proportionality assumption. More specifically: if we find only the variable control to be significant in our estimated hazard function then this implies that the effect of the treatment has a lasting proportional effect; in contrast if we find only the time varying variable interview tv to be significant, this means that the control group are only distinct from the treatment group for the period of 6-12 months unemployment and after they have received their first Restart interview they become indistinguishable from the treatment group; if both effects are significant then the interpretation is that both the short term and longer run effects of the treatment are significant.

Our results for the independent competing risks Cox proportional hazards model are presented in Table I. For clarity we discuss mainly the preferred specifications. ${ }^{15}$ The results justify the use of the competing risks model, as distinct factors play an important role in influencing the probability of exiting from unemployment depending on exit type. The modelling considerations introduced above of: the proxy variables for the arrival rate of offers and the experimental design complication, necessitating the use of a time-varying covariate also prove to provide significant insights into the process by which individuals leave unemployment. The other conditioning variables have the expected signs with the presence of a working partner reducing the probability of exiting unemployment, while good local labour market conditions and education increase the likelihood of ending a spell of unemployment. The effect of the predicted benefit level ${ }^{16}$ is also clear in that higher levels of predicted

14 In principle the same argument would suggest that the variables job offer and training offer be included as time varying regressors. However, this is not possible as information on the job and training offers received at the 12 months Restart interview was not available for our sample.

15 For each exit type we estimated an unrestricted model which included both control and interview tv and a restricted model in which the coefficient on interview tw was set equal to zero. The reported equations are those preferred based on the relevant likelihood ratio tests. Details of the likelihood function values and the alternative estimates of the coefficients of interest are provided in Table A $\mathrm{r}$.

${ }^{16}$ It was necessary to use predicted benefits as actual benefits were missing on those who left unemployment between the Restart interview and the survey date. The equation used to predict benefit levels is reported in a supplementary appendix available from the authors on request. The equation is identified by an exclusion restriction relating to the variable indicating whether the person was living alone. Clearly, such a variable affects benefits but one would not expect such a variable, a priori on its own, (given that family status, and active partner are included as controlling regressors) to influence unemployment duration. 
benefits reduce the probability of exiting unemployment. While these are important issues, in this paper we wish to concentrate on the role of Restart in reducing unemployment.

To understand the implications of our results for Restart we consider first the coefficients for the 'training' exit from unemployment. The results suggest that the use of either the control dummy or the time-varying covariate are insignificant in the determination of the hazard of unemployment exit to training. The main reason for this result becomes clear when we examine the coefficient of the training offer variable, which suggests that the predominant influence on exits to training is the receipt of a training offer. This result clearly makes sense and suggests that propensity to exit to training is mainly conditioned on such an offer and its timing is not greatly influenced by being in the control group over and above the reception of such offers. The table also provides details of the other significant positive influences on this exit probability which are: being male, young, married or divorced with children (who are not younger than school age), not having a partner in work, not having a driving licence and living in rented accommodation.

The estimated coefficients for the 'signing-off' exit indicate that the time varying variable associated with having had an interview, interview $t v$, is positively significantly in the hazard, while the control variable is insignificant. The implication of this finding is that the effect of being in the control group for the signing-off exit is not proportional. Hence we may deduce that the effect on the hazard for signing-off is crucially dependent on the timing of the first Restart interview. More specifically, having the first interview gives a large and positively significant boost to the hazard for signing-off unemployment. An interpretation of this finding is that there exists a group of unemployment benefit claimants, who if challenged about their availability for work, would end up signing off - since they are not really eligible for work. In this instance the Restart interview, and associated entitlement check, will identify these individuals irrespective of when the interview takes place, leading to a jump in the number moving off the register.

There are other interesting differences in the effects of the controlling regressors for the signing-off exit compared to the 'training' exit and the 'job' exit. The most important of these effects is that the people who sign off are much more likely to be women and they are much less likely to have received any offers of training course placements. In contrast men are much more likely than women to exit unemployment to a job or a training placement. Since gender is clearly working in a different way for distinct exits we also estimated our equations separately for men and women. Unfortunately there are only go women in the control group and the data proved insufficient to support any significant control group effects. The results for the males only equations for the main variables of interest are reported in Table $\mathrm{A}_{\mathrm{I}}$. They provide very similar conclusion to those discussed for the whole sample.

Results for the job exit regime presented in the first column of Table I indicate that the effect of being in the control group is proportional and significant, i.e. the interpretation is that the assignment to the control group

(C) Royal Economic Society 1996 
Table I ,

Independent Competing Risks Cox Proportional Hazard Regression

\begin{tabular}{|c|c|c|c|}
\hline Regressor & $\begin{array}{c}\text { Job exit } \\
\text { coefficient (s.E.) }\end{array}$ & $\begin{array}{l}\text { Training exit } \\
\text { coefficient (s.E.) }\end{array}$ & $\begin{array}{l}\text { Signing-off exit } \\
\text { coefficient (s.E.) }\end{array}$ \\
\hline Benefit entitlement & $\begin{array}{c}-0.15123^{* *} \\
(0.00793)\end{array}$ & $\begin{array}{c}-0 \cdot 16001^{* *} \\
(0.01623)\end{array}$ & $\begin{array}{c}-0.10627^{* * *} \\
(0.01170)\end{array}$ \\
\hline Control & $\begin{array}{c}-0.2844^{* * *} \\
(0.12443)\end{array}$ & $\begin{array}{l}-33804 \\
(0.2162 \mathrm{I})\end{array}$ & $\begin{array}{c}0.3892 \\
(0.2828)\end{array}$ \\
\hline Interview tv & - & - & $\begin{array}{l}0^{*} 7243^{* * *} \\
\left(0^{*} 3573\right)\end{array}$ \\
\hline Job offer & $\begin{array}{l}0^{\circ} 56143^{* *} \\
(0.14595)\end{array}$ & $\begin{array}{r}-0.36097 \\
(0.505 \text { 19) }\end{array}$ & $\begin{array}{c}-0.82175 \\
(0.45207)\end{array}$ \\
\hline Training offer & $\begin{array}{c}-1.0509 * * \\
\left(0^{*} 15^{2} 4^{8}\right)\end{array}$ & $\begin{array}{l}1.9608 * * \\
(0.10225)\end{array}$ & $\begin{array}{c}-0.44630^{* * *} \\
\left(0^{\circ} 199 \text { I5) }\right.\end{array}$ \\
\hline Sex & $\begin{array}{l}0.61984^{* *} \\
(0.07469)\end{array}$ & $\begin{array}{l}0.74^{86} 7^{* *} \\
\left(0.13^{887}\right)\end{array}$ & $\begin{array}{c}-0.2825^{1 * *} \\
(0.11468)\end{array}$ \\
\hline Age 25 & $\begin{array}{c}0.7274^{* *} \\
(0.09087)\end{array}$ & $\begin{array}{l}0.75128^{* *} \\
(0.15472)\end{array}$ & $\begin{array}{c}0.406 \text { 1** } \\
(0.14874)\end{array}$ \\
\hline Age 35 & $\begin{array}{l}0^{\circ} 56259^{* * *} \\
\left(0^{*} 10866\right)\end{array}$ & $\begin{array}{l}0.78045^{* *} \\
(0.1812)\end{array}$ & $\begin{array}{l}0.39140^{* * *} \\
\left(0^{\circ} 175^{26}\right)\end{array}$ \\
\hline Age 45 & $\begin{array}{c}-0.05575 \\
(0.1093 \mathrm{I})\end{array}$ & $\begin{array}{r}-0.00789 \\
(0.19915)\end{array}$ & $\begin{array}{c}-0.01024 \\
(0.17557)\end{array}$ \\
\hline Age 55 & $\begin{array}{r}-1.4806 * * \\
\left(0.1355^{2}\right)\end{array}$ & $\begin{array}{r}-1.7678^{* *} \\
(0.31539)\end{array}$ & $\begin{array}{c}0.06254 \\
(0.1805)\end{array}$ \\
\hline Married & $\begin{array}{c}3^{\cdot 800} 3^{* *} \\
\left(0.2214^{2}\right)\end{array}$ & $\begin{array}{l}3.3371^{* *} \\
(0.41680)\end{array}$ & $\begin{array}{l}3.0891 * * \\
\left(0 \cdot 3335^{2}\right)\end{array}$ \\
\hline Divorced & $\begin{array}{l}\text { r.0or } 6 * * \\
(0.13139)\end{array}$ & $\begin{array}{l}0.66565^{* *} \\
(0.21854)\end{array}$ & $\begin{array}{c}1.2613^{* *} \\
(0.20322)\end{array}$ \\
\hline Dependent children & $\begin{array}{c}1 \cdot 340^{* *} \\
(0.08262)\end{array}$ & $\begin{array}{l}\text { I.536** } \\
(0.16021)\end{array}$ & $\begin{array}{l}0^{\circ} 74^{\circ} 44^{* *} \\
\left(0^{\circ} 13137\right)\end{array}$ \\
\hline Toddlers & $\begin{array}{c}-0.70279^{* *} \\
(0.07954)\end{array}$ & $\begin{array}{c}-0.67133^{* *} \\
(0.13821)\end{array}$ & $\begin{array}{l}\text { o.09405 } \\
\left(0^{*}+11735\right)\end{array}$ \\
\hline Local unemployment & $\begin{array}{c}1 \cdot 808^{* * *} \\
\left(0^{*} 49728\right)\end{array}$ & $\begin{array}{l}1 \cdot 3869 \\
(0.93107)\end{array}$ & $\begin{array}{c}\text { I.568 } 7 * * \\
(0 \cdot 76659)\end{array}$ \\
\hline Inner city & $\begin{array}{c}-0.21828^{* *} \\
(0.0818)\end{array}$ & $\begin{array}{c}0.07749 \\
\left(0.1275^{2}\right)\end{array}$ & $\begin{array}{r}-0.19045 \\
(0.1276)\end{array}$ \\
\hline Race & $\begin{array}{c}0.26945 \\
(0 \cdot 239 \text { Io) }\end{array}$ & $\begin{array}{c}0.0728 \\
(0.38604)\end{array}$ & $\begin{array}{c}0^{\circ} 1644^{6} \\
\left(0^{\circ} 35920\right)\end{array}$ \\
\hline Education & $\begin{array}{l}0.25665^{* *} \\
(0.06322)\end{array}$ & $\begin{array}{l}0.1543 \\
(0.10547)\end{array}$ & $\begin{array}{r}-0.08088 \\
(0.09525)\end{array}$ \\
\hline Driver & $\begin{array}{l}0.37684^{* * *} \\
(0.06237)\end{array}$ & $\begin{array}{c}-0.23713^{* *} \\
(0 \cdot 10950)\end{array}$ & $\begin{array}{c}\text { o.070 74 } \\
(\text { o.095 27) }\end{array}$ \\
\hline LA house & $\begin{array}{l}0.8308^{* *} \\
(0.10008)\end{array}$ & $\begin{array}{l}\text { I.4024** } \\
\text { (o.2 I 599) }\end{array}$ & $\begin{array}{l}\text { o. } 59911 * * \\
\left(0^{*} 13207\right)\end{array}$ \\
\hline Rent house & $\begin{array}{l}1 \cdot 1402 * * \\
(0 \cdot 12344)\end{array}$ & $\begin{array}{c}1^{*} 5944^{* *} \\
\left(0 \cdot 24^{8} 57\right)\end{array}$ & $\begin{array}{l}0.77163^{* *} \\
(0.18720)\end{array}$ \\
\hline Other house & $\begin{array}{c}-0.52045^{* *} \\
(0.2360)\end{array}$ & $\begin{array}{r}-0.88571 \\
(0.58308)\end{array}$ & $\begin{array}{c}-0.39695 \\
\left(0^{\circ} 36591\right)\end{array}$ \\
\hline Past unemployment & $\begin{array}{c}-0.49735^{* *} \\
(0.12604)\end{array}$ & $\begin{array}{r}-0^{*} 25768 \\
\left(0^{*} 20433\right)\end{array}$ & $\begin{array}{c}-0.6723^{* * *} \\
\left(0.2059^{2}\right)\end{array}$ \\
\hline Active partner & $\begin{array}{c}-5.1103^{* *} \\
(0.30564)\end{array}$ & $\begin{array}{c}-5.9025^{* *} \\
(0.61285)\end{array}$ & $\begin{array}{c}-33400 * * \\
(0.44827)\end{array}$ \\
\hline Log likelihood & $-10175^{\circ} 013$ & -3193.5698 & -4309.03 \\
\hline Number of observations & 4,728 & 4,728 & 4,728 \\
\hline chi squared (23) & $729 \cdot 98$ & $55^{1 \cdot 27}$ & $4^{82} \cdot 5^{1}$ \\
\hline
\end{tabular}

Asymptotic standard errors are given in parentheses.

** Indicates significance at $\mathrm{I} \%$ level. 
has a lasting proportional downward shift on the baseline hazard. A specification in which the time varying covariate was excluded could not be rejected indicating that the effect does not dissipate after 6 months. One interpretation of this finding is that if an individual is assigned to a group which does not have a Restart interview at 6 months then this has a lasting effect on unemployment, i.e. the ground lost to those who received the interview at 6 months of unemployment is not made up subsequently. From this it would appear, that in terms of possible exits into a job, the opportunity of a first Restart interview at 12 months is not a satisfactory substitute for the same interview 6 months earlier. One possible explanation for this result is that employers look on potential employees who have had 12 months unemployment as significantly less 'employable' than their counterparts who present themselves for interview at a much earlier stage in their unemployment history.

\section{GONCLUSION}

In this paper we examine the impact of the Restart programme in reducing unemployment duration. The data used in this paper are well suited to this type of analysis, in that they include a randomly assigned control group, members of which were excluded from the Restart process. The availability of a control group helps overcome the sample-selection issues which have hindered previous attempts to evaluate government intervention in various areas e.g. training programmes. The results of our paper show that interventionist government policy can lead to a substantial reduction in time spent unemployed in the short run.

Examining the time spent unemployed by individuals we find that inclusion in the Restart process significantly decreases the probability of remaining unemployed over the sample period. To do this we estimate a competing risk model with three different types of exit from unemployment: job exits, training exits and signing-off UB, exits. The empirical estimates suggest that the hazards associated with exits to these separate states are very distinct. Specifically, we find that the effect of the Restart interview on exit from unemployment into training is small if one includes a proxy for the arrival rate of training offers. Exit to the state of 'not signing-on' seems to be common amongst women and other groups who are most likely not to be genuinely available for work. Our estimation found that the Restart interview scared these people into signing-off and that the timing of this exit was most clearly associated with their first Restart interview which acted as a check on work availability. Hence, it was no surprise to find that control group's first interview at 12 months of unemployment was most comparable to the treatment group's first interview at 6 months of unemployment.

Perhaps the most important finding of the competing risks model was to establish that the hazard for exit to a job is significantly different for the treatment and control groups over the 18 month period of the study. The implication of this finding is that exclusion from an initial Restart interview would seem to have a lasting (proportional) detrimental effect on the control 
group's conditional probability of exit from unemployment to a job. This finding raises an important question of whether conducting an experiment which permanently effects someone's lifetime prospects is ethically justifiable.

\section{University of Newcastle-upon-Tyne}

\section{Maynooth College, Co Kildare}

\section{REFERENCES}

Burdett, K., Kiefer, N., Mortensen, D. and Neumann, G. (1984). 'Earnings, unemployment, and the allocation of time over time.' Review of Economic Studies, vol. $5^{1}$ pp. 559-78.

Child Poverty Action Group (1993). Rights Guide to Non-Means-Tested Benefits, 16 th edition. London: CPAG Ltd.

Dolton, P. J. and O'Neill, D. (1995). 'The Restart effect and the return to full time stable employment' (mimeo)

Han, A. and Hausman, J. (1990). 'Flexible parametric estimation of duration and competing risk models.' Journal of Applied Econometrics, vol. 5, pp. $1-28$.

HMSO (r 994$)$. 'Jobseeker's allowance.' Department of Social Security and Employment Department.

Johnson, T. R. and Klepinger, D. H. (r 994). 'Experimental evidence on unemployment insurance worksearch policies.' Journal of Human Resources, vol. 29, no. 3, pp. 695-717.

Katz, L. and Meyer, B. (1990). 'Unemployment insurance, recall expectations, and unemployment outcomes.' Quarterly Journal of Economics, vol. 105, pp. 973-1002.

LaLonde, R. ( 1985 ). 'Evaluating the econometric evaluations of training programs with experimental data.' American Economic Review, vol. 76, no. 4, pp. 6o4-20.

Lancaster, T. (1979). 'Econometric methods for the duration of unemployment.' Econometrica, vol. 47, pp. $939-56$.

Lancaster, T. and Chesher, A. (1983). 'The econometric analysis of reservation wages.' Econometrica, vol $5^{\mathrm{I}}$, pp. $1661-76$.

Meyer, B. (1990). 'Unemployment insurance and unemployment spells.' Econometrica, vol. 58, pp. 757-82.

Royston, G. D. ( 1983 ). 'Wider application of survival analysis: an evaluation of an unemployment benefit procedure.' The Statistician, vol. 32 , pp. 301-6.

Royston, G. D. (1984). 'Public sector experimentation: an evaluation of the impact of a social security operation.' Journal of the Operations Research Society, vol. 35, no. 8, pp. 711-8.

White, M. and Lakey, J. (1992). 'The Restart effect: does active labour market policy reduce unemployment?' London: Policy Studies Institute.

Woodbury, S. A. and Spiegelman, R. G. (1987). 'Bonuses to workers and employers to reduce unemployment: randomized trials in Illinois.' American Economic Review vol. 77, no. 4, pp. 513-30. 


\section{DATA APPENDIX. VARIABLE DESCRIPTION}

\section{Means for control group and treatment group respectively are given in parentheses}

Inner City: Inner City identifier $(\mathrm{I}=$ inner city) $(0.220,0.179)$.

Sex: Sex $(1=$ male, $0=$ female $)(0.679,0.675)$.

Past Unemployment: Proportion of the individuals working life since 1982 which was spent in unemployment, calculated from JUVOS data. $\left(0^{*} 390,0^{*} 391\right)$.

Duration: Continued duration of current unemployment spell (months) beyond the sample date, calculated from JUVOS. (13, 12).

Dep. Kids: Total number of dependent children (aged less than 16). (0.508, 0.517$)$.

Toddler: Total number of toddlers (aged less than 5) (o*259, 0*286).

Local Unempl: For each 1978 job centre travel to work area (jcttwa) this measures the percentage decline in unemployment between 1988 and 1990 ( Log of average local unemployment in $1988-\log$ of average local unemployment in 1990). $\left(0^{*} 347,0^{*} 34^{8}\right)$ We use the difference in unemployment levels as a measure of local labour market conditions as unemployment rates are not available from NOMIS for the 1978 jettwa.

Control: Restart sub-group ( $\mathrm{I}=$ control).

Driver: Do you hold a current drivers licence $\left(\mathrm{I}=\right.$ yes) $\left(0^{\circ} 5_{16} 6.0^{*} 49^{8}\right)$.

Married: Married ( $\mathrm{I}=$ yes) $\left(0^{*} 45^{1}, 0^{*} 47^{2}\right)$.

Divorced: Divorced/separated/widowed $(\mathrm{I}=$ yes $)(0 \cdot 13 \mathrm{I}, \mathrm{o} \cdot \mathrm{I} \mathrm{O} \mathrm{I})$.

Race: Race of respondent ( $1=$ white) $(0.971,0.980)$.

Education: Any academic or technical qualification. $(\mathrm{r}=$ yes $)\left(0^{*} 562,0^{*} 55^{\circ}\right)$.

Active Partner: Partner working (full or part-time) $\left(\mathrm{I}=\right.$ yes) $\left(\mathrm{O}^{*} 250,0^{*} 223\right)$.

Benefit Entitlement: Predicted benefit entitlement. ( $\left.£ 42^{\circ} \cdot 96, £ 43.79\right)$.

Rent House: Rent house from Housing Association etc. (privately) ( $1=$ yes) (o.12, o.095).

LA House: Rents accommodation from Local Authority $(\mathrm{I}=$ yes $)\left(0_{25}, 0 \cdot 24 \mathrm{I}\right)$.

Own House: Own/buying house on mortgage (o.30, o.30).

Other House: Other form of accommodation other than homeowner, renting from Local Authority or renting privately (e.g. living rent free, squatting.) ( $\mathrm{I}=$ yes) (0.0 I 7 , o.0 I),

Interview $t v$ : Time varying covariate taking the value zero in months preceding the first Restart interview and one thereafter.

Job Offer: Did you receive a job offer as result of the Restart interview ( $\mathrm{I}=$ yes) ( $0^{\circ} \mathrm{o}$, $\mathrm{O}^{\circ} \mathrm{O} 2$ ).

Training Offer: Did you receive an offer of a place on a training scheme as a result of the Restart interview ( $\mathrm{I}=$ yes) $(\mathrm{O}, \mathrm{O} \cdot \mathrm{I} \mathrm{I})$.

Age 25: A dummy variable taking the value $\mathrm{I}$ if the individual is aged between 25 and 35. Similar definitions apply to Age 35 and Age 45 while Age 55 indicates individuals aged 55 or over.

Note: The reference groups for the age and housing dummy variables used in Table A 1 , were whether the individual was aged less than 25 and whether or not the individual owned their own house. 
Table A I

Alternative Specifications of the Hazard along with the Results for Males only

\begin{tabular}{|c|c|c|c|c|c|}
\hline Exit state & Variable name & (I) All & (2) All & (1) Males & (2) Males \\
\hline Log likelihood & $\begin{array}{l}\text { Control } \\
\text { Interview tv } \\
\text { Job offer } \\
\text { Training offer }\end{array}$ & $\begin{array}{c}-0.2844^{* *} \\
(0.0079) \\
- \\
0.5614^{* *} \\
(0.14595) \\
-1.0509^{* *} \\
\left(0^{\circ} 15^{2} 4^{8}\right) \\
-10175^{\circ} .13\end{array}$ & $\begin{array}{c}-0.2059 \\
\left(0^{\circ} 3263\right) \\
0.0912 \\
\left(0^{\circ} 35^{26}\right) \\
0.560^{* *} \\
\left(0.14^{60}\right) \\
-1.0511^{* *} \\
\left(0.15^{25}\right) \\
-10174.98\end{array}$ & $\begin{array}{c}-0.2931^{*} \\
(0.1578) \\
- \\
0.6102^{* *} \\
(0.1811) \\
-1.0764^{* *} \\
(0.1902) \\
-6112.63\end{array}$ & $\begin{array}{c}-0.3105 \\
(0.4605) \\
-0.0197 \\
(0.4895) \\
0.6103^{* *} \\
(0.1811) \\
-1.0764^{* *} \\
(0.1902) \\
-6112.63\end{array}$ \\
\hline Training exit & $\begin{array}{l}\text { Control } \\
\text { Interview tv } \\
\text { Job offer } \\
\text { Training offer }\end{array}$ & $\begin{array}{c}\text { o.33804 } \\
(0.2162) \\
- \\
-0.36097 \\
(0.50519) \\
\text { I.9608** } \\
(0.10225)\end{array}$ & $\begin{array}{c}0.8429^{*} \\
\left(0^{*} 4347\right) \\
0.6288 \\
(0.4959) \\
-0^{\circ} 3647 \\
\left(0^{\circ} 5052\right) \\
\text { I.959o** } \\
\left(0^{\circ} 1023\right)\end{array}$ & $\begin{array}{c}0.4626^{*} \\
\left(0^{*} 244^{8}\right) \\
- \\
-0.3640 \\
(0.5845) \\
1.965^{* *} \\
(0.1215)\end{array}$ & $\begin{array}{c}\text { I.009** } \\
(0.4802) \\
0.6870 \\
(0.5513) \\
-0.3688 \\
(0.5845) \\
1 \cdot 9635^{* *} \\
(0.1215)\end{array}$ \\
\hline Log likelihood & & -3193.57 & $-3 \operatorname{19} 2 \cdot 84$ & $-2184.8 \mathrm{I}$ & $-2184 \cdot 10$ \\
\hline Signing-off exit & $\begin{array}{l}\text { Control } \\
\text { Interview to } \\
\text { Job offer } \\
\text { Training offer }\end{array}$ & $\begin{array}{c}-0.8129^{*} \\
\left(0^{*} 45^{21}\right) \\
-0.446^{* *} \\
\left(0^{\circ} 199^{2}\right) \\
-43^{10.97}\end{array}$ & $\begin{array}{c}0^{*} 3893 \\
\left(0^{*} 2829\right) \\
0^{*} 7244^{* *} \\
\left(0^{*} 3573\right) \\
-0.8218 * \\
(0.4521) \\
-0.4463^{* *} \\
\left(0^{*} 199^{2}\right) \\
-4309.03\end{array}$ & $\begin{array}{c}-1 \cdot 2833 \\
(1 \cdot 0056) \\
-0.1081 \\
(0.2715) \\
-1862 \cdot 23\end{array}$ & 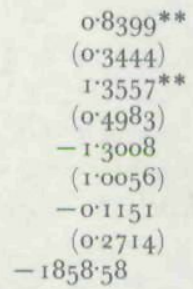 \\
\hline$N$ & - & 4,565 & 4,565 & 3,076 & 3,076 \\
\hline
\end{tabular}

Standard errors are given in parentheses.

* Indicates significance at the $5 \%$ level.

** Indicates significance at the $1 \%$ level. 
Copyright of Economic Journal is the property of Blackwell Publishing Limited. The copyright in an individual article may be maintained by the author in certain cases. Content may not be copied or emailed to multiple sites or posted to a listserv without the copyright holder's express written permission. However, users may print, download, or email articles for individual use. 